\title{
Update on D2E7: a fully human anti-tumour necrosis factor $\alpha$ monoclonal antibody
}

\author{
Joachim Kempeni
}

Rheumatoid arthritis (RA) is characterised by persistent joint inflammation and concomitant joint destruction, and in severe cases with extra-articular manifestations, multiple joint involvement, and a significant reduction in life expectancy. In addition, functional decline and disability inevitably accompanies joint destruction. The extent to which most standard medical approaches have a positive impact on the course of rheumatoid disease is the subject of debate. ${ }^{1}$ Intense research effort has focused on understanding cellular inflammatory mechanisms that may serve as therapeutic targets.

Tumour necrosis factor $\alpha(\mathrm{TNF} \alpha)$ is a pleiotropic cytokine overproduced in rheumatoid joints primarily by macrophages. ${ }^{2}$ Although the causes of RA are not fully understood, $\mathrm{TNF} \alpha$ seems to play a cardinal part in a variety of events in inflammatory synovitis and articular matrix degradation, ${ }^{3}$ and is therefore a prime target for directed immunotherapy in RA. ${ }^{45}$ Accordingly, antibodies and soluble TNF receptors that bind $\mathrm{TNF} \alpha$ with high specificity neutralise its activity and have been developed for use as therapeutic agents. However, current anti-TNF $\alpha$ treatments for RA may be limited by their capacity to elicit immune responses to their non-human elements or artificially fused human sequences. ${ }^{6}$ The high specificity neutralisation potency of a previously perfected murine monoclonal antibody was transferred to a fully human IgG1 antibody format (D2E7).

D2E7, a high affinity, recombinant, fully human anti-TNF $\alpha$ has no non-human or artificially fused human sequences. Therefore, D2E7 may have low immunogenicity and possibly greater therapeutic potential. ${ }^{6}$ D2E7 effectively neutralised a broad range of TNF biological activities both in vitro and in vivo. For example, D2E7 inhibited binding of human $\mathrm{TNF} \alpha$ to its $\mathrm{p} 55$ and $\mathrm{p} 75$ receptors on human cells and is highly selective for $\mathrm{TNF} \alpha$. It prevented severe polyarthritis in human $\mathrm{TNF} \alpha$ expressing transgenic mice in a dose dependent manner and is currently being evaluated in clinical trials to treat RA. ${ }^{\text {? }}$

Phase I studies

Several randomised, placebo controlled phase I trials have evaluated the safety and efficacy of
D2E7 (table 1). All studies enrolled patients with longstanding, active RA. Efficacy was assessed using composite criteria, such as the American College of Rheumatology improvement criteria (ACR20). Study DE001 was the first exposure of patients to intravenous D2E7 treatment. After completing the double blind portion of the trial, patients were offered the opportunity to continue open label long term D2E7 treatment (DE003). Weekly subcutaneous administration of D2E7 was evaluated in study DE004. As monotherapy is often inadequate to control symptoms and rapid progression of RA, study DE010 evaluated D2E7 (1 $\mathrm{mg} / \mathrm{kg}$ as a single subcutaneous or intravenous injection) as combination treatment in patients whose stable dose of MTX (median dose, 15 $\mathrm{mg} /$ week) was insufficient to control symptoms.

In these three phase I therapeutic trials, 198 patients have been treated with D2E7 as a single agent and in combination with MTX. The mean ages of patients ranged from 53 to 60 years, the mean duration of RA extended from 10 to 12 years, and the mean number of previous disease modifying antirheumatic drugs (DMARDs) received by patients in the trials was approximately 3.5. Used alone, single and multiple dose treatment with D2E7 produced ACR20 response in between $56 \%$ and $80 \%$ of patients. In contrast, the proportion of placebo treated patients achieving ACR20 response ranged from $0 \%$ to $16 \%$. The therapeutic effects of D2E7 became evident within 24 hours to one week after administration and reached maximum effect after one to two weeks, with dose response plateauing at 1 $\mathrm{mg} / \mathrm{kg}$ D2E7. Subcutaneously and intravenously administered D2E7 provided similar D2E7 plasma levels and comparable ACR20 response rates. At a dose of $1 \mathrm{mg} / \mathrm{kg}$, subcutaneous and intravenous administrations were safe and efficaceous when given with standard, stable doses of MTX. In the long term open label extensions, a high percentage of patients continued to receive treatment with D2E7 indicating that long term treatment with $\mathrm{D} 2 \mathrm{E} 7 \mathrm{in}$ the dose range from 0.5 to $10 \mathrm{mg} / \mathrm{kg}$ was well tolerated.
Department of Clinical Oncology/Immunology, Knoll AG-BASF

Pharma, Knollstrasse, D-67008 Ludwigshafen, Germany

Correspondence to: Dr Kempeni

(joachim.kempeni@ knoll-ag.de)
Table 1 Phase I randomised, double blind, placebo controlled studies

\begin{tabular}{lllll}
\hline Study number & $\begin{array}{l}\text { Number of patients } \\
\text { receiving D2E7 }\end{array}$ & Dose and route of administration & $\begin{array}{l}\text { Concurrent } \\
\text { DMARD }\end{array}$ & $\begin{array}{l}\text { Maximum ACR } \\
\text { 20 response }\end{array}$ \\
\hline DE001/003 & 120 & $\begin{array}{l}\text { Single and multiple iv injections, ascending doses } \\
\text { ranging from } 0.5 \text { to } 10 \mathrm{mg} / \mathrm{kg}\end{array}$ & No & $80 \%$ \\
DE004 & 24 & $\begin{array}{l}\text { Weekly } 0.5 \mathrm{mg} / \mathrm{kg} \text { sc injections } \\
\text { Single iv or sc injection of } 1 \mathrm{mg} / \mathrm{kg}\end{array}$ & No & $70 \%$ \\
DE010 & 54 & MTX & $67 \%$ \\
\hline
\end{tabular}

MTX = methotrexate $;$ iv = intravenous; sc $=$ subcutaneous DMARD $=$ disease modifying antirheumatic drug. ${ }^{\star}$ With subcutaneous administration. 
Table 2 Effect of treatment with D2E7 on radiographic progression scores

\begin{tabular}{|c|c|c|c|}
\hline & \multirow[b]{2}{*}{ Baseline } & \multicolumn{2}{|c|}{ Duration of D2E7 treatment } \\
\hline & & 6 months & 12 months \\
\hline Disease duration (y) & 12.1 & 12.6 & 13.1 \\
\hline Ratingen score ${ }^{\star}$ & 35.0 & 35.0 & 35.5 \\
\hline Sharp erosion score ${ }^{\star}$ & 49.5 & 45.0 & 47.0 \\
\hline Sharp JSN score* & 47.5 & 49.0 & 48.0 \\
\hline
\end{tabular}

${ }^{\star}$ Median values. JSN = joint space narrowing.

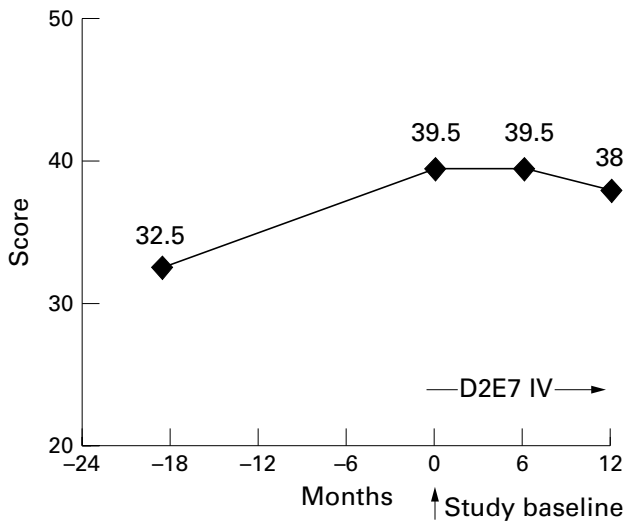

Figure 1 Effect of D2E7 on ratingen radiological progression score in 22 patients with films before study enrollment.

\section{Arrest of radiographic progression}

The arrest of radiographic progression is an extremely important outcome parameter in RA with the link between radiographic progression and disability being clearly established by several studies. ${ }^{8}$ A substudy of DE001/003, included radiological evaluation in patients completing 12 months of treatment with MET. In the 66 patients with a complete set of films during the 12 month study period, no radiographic progression was observed during D2E7 treatment (table 2), providing evidence that D2E7 is a disease modifying drug. For 22 of these patients, pretreatment radiographs (mean 19 months before start of D2E7 treatment) were available and significant radiographic progression was shown before initiation of D2E7 whereas no significant progression could be shown after initiation of D2E7 treatment, which provided further evidence that D2E7 treatment can arrest radiographic progression (fig 1). These results need confirmation in a prospective phase III trial.

Effects on pro-matrix metalloproteinases The pro-matrix metalloproteinases (proMPPs) play key parts in mediating inflammation and joint destruction in RA. ${ }^{9}$ The effects of D2E7 on levels of pro MPP-1 and 3 were investigated in a group of patients who took part in DE001/003. Pro-MMP1 and proMMP3 serum levels decreased by up to $50 \%$ within the first six months of D2E7 treatment (fig 2).

\section{Phase II study}

The dose response relation of placebo and D2E7 (20, 40, and $80 \mathrm{mg}$ ), given in a double blind fashion as weekly subcutaneous injec-

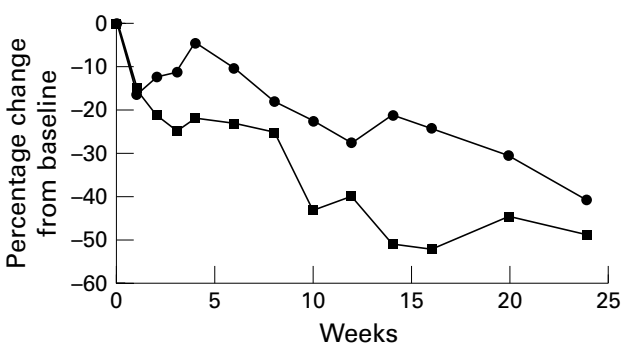

Figure 2 Effect of treatment with D2E7 on pro-matrix metalloproteinases (pro-MMP 1: solid square; pro-MMP 3: metalloproteind circle).
solid

tions, was evaluated in study DE007. A total of 283 patients were randomised into the trial. The mean age of patients was 52 years and the mean duration of RA was 10 years. Patients had previously taken a mean of 3.8 DMARDs. All three doses of D2E7 were efficacious (49\% to $57 \%$ of patients achieved ACR2 0 responder status compared with $10 \%$ with placebo, $\mathrm{p}<0.0001$ ) and no dose response relation was apparent at month 3 .

\section{Safety}

Patients with RA have been treated with intravenous and subcutaneous D2E7 for more than 12 months. Treatment with D2E7 has been well tolerated. The rate and severity of adverse events were comparable between all dosage groups of D2E7 and placebo. Large long term phase III trials comparing D2E7 with placebo or MTX are underway to further investigate the safety and efficacy of this fully human antiTNF antibody.

\section{Conclusion}

Collectively, these early data suggest that the fully human anti-TNF $\alpha$ antibody D2E7 is safe and effective as monotherapy or in combination with MTX when administered by single and multiple intravenous and subcutaneous injections. Additional studies are underway to further define optimal use of this novel treatment.

1 Brooks P. Clinical management of rheumatoid arthritis. Lancet 1993;341:286-90.

2 Fox D. Cytokine blockade as a new strategy to treat rheumatoid arthritis: inhibition of tumor necrosis factor. Arch Intern Med 2000;160:437-44.

3 Feldmann M, Brennan F, Chu C, et al. Does TNF-a have a pivotal role in the cytokine network in rheumatoid arthritis? In: Friers W, ed. Tumor necrosis factor: molecular and cellular biology and clinical relevance. Basel: Karger, 1993:144-52.

4 Maini R, Brennan F, Williams R, et al. TNF-a in rheumatoid arthritis and prospects of anti-TNF therapy. Clin Exp Rheumatol 1993;11 (suppl 8):S173-5.

5 Warzocha K, Bienvenu J, Coiffier B, Salles G. Mechanisms of action of the tumor necrosis factor and lymphotoxin of action of the tumor necrosis factor and lymphotoxin
ligand-receptor system. Eur Cytokine Netw 1995;6:83-96.

6 Kavanaugh AF. Anti-tumor necrosis factor-alpha monoclonal antibody therapy for rheumatoid arthritis. Rheum Dis Clin North Am 1998;24:593-614.

7 Kempeni J. Preliminary results of early clinical trials with the fully human anti-TNF alpha monoclonal antibody D2E7. Ann Rheum Dis 1999;58 (suppl):I70-2.

8 Scott D, Pugner K, Kaarela K, et al. The links between joint damage and disability in rheumatoid arthritis. Rheumatology 2000;39:122-32.

9 Keyszer G, Lambiri I, Keysser M, et al. Matrix metalloproteinases, but not cathepsins $\mathrm{B}, \mathrm{H}$, and $\mathrm{L}$ or their inhibitors in peripheral blood of patients with rheumatoid arthritis are potentially useful markers of disease activity. Z Rheumatol 1998;57:392-8. 